\title{
Building a Social Governance Pattern of Co-Construction, Common Governance and Sharing under the New Normal
}

\author{
Fengyan Li \\ Jinan University, Guangzhou, China \\ Email:1lifengyan@163.com
}

How to cite this paper: Li, F. Y. (2020). Building a Social Governance Pattern of Co-Construction, Common Governance and Sharing under the New Normal. Open Journal of Social Sciences, 8, 194-203. https://doi.org/10.4236/jss.2020.83017

Received: February 10, 2020

Accepted: March 13, 2020

Published: March 16, 2020

Copyright $\odot 2020$ by author(s) and Scientific Research Publishing Inc. This work is licensed under the Creative Commons Attribution International License (CC BY 4.0).

http://creativecommons.org/licenses/by/4.0/

\section{(c) (i) Open Access}

\begin{abstract}
The report of the $19^{\text {th }}$ National Congress of the Communist Party of China proposed to "build a social governance pattern of co-construction, governance and sharing". It fully reflects the party's further understanding of the laws of contemporary Chinese social governance and the rules of socialist social construction, and is conducive to promoting effective social governance and a good social order. However, in the context of the new era, it is not easy to create a sharing social governance that people can share the results of governance. Therefore, it is necessary to clarify the concept and the dilemma of building the social governance pattern of co-construction and co-governance and sharing, and explore its realization path.
\end{abstract}

\section{Keywords}

New Normal, Co-Construction, Co-Governance, Sharing, Social Governance Pattern

\section{Introduction}

In the context of the new era, social governance theory has been endowed with new connotations. The idea of "creating a social governance pattern of co-construction, governance and sharing" proposed by the report of the $19^{\text {th }}$ National Congress of the Communist Party of China enriched and innovated the content of social governance work. The transition from social management to social governance, and then from the social governance pattern of "co-construction and sharing" to the social governance pattern of "co-construction and co-government sharing" highlights the collective efforts and wisdom of the whole party and the nation's people in exploring social governance (Li, 2017), and it reflects 
the people-centered idea. So, it is of great significance to fully discuss the concept and necessity of it, as well as the problems encountered in building the social governance pattern of co-construction and co-governance and sharing.

\section{Definition}

Co-construction refers to the participation of social construction subjects in social construction (Li, 2017). Co-construction means that there are multiple subjects, which indicates that the government, market, and society are important subjects in the process of social governance. In the concept of co-construction and co-governance and sharing, co-construction is the foundation, highlighting the fundamental and strategic position of institutions and systems in the social governance structure. The reason for co-construction is to meet the needs of the people for a better life, to respond to changes in the mode of economic development, and to adapt to social modernization at home and abroad (Jiang \& Liu, 2018).

Co-governance means participating in social governance together. Co-governance is the key. It is required to establish a large social outlook and a large governance outlook, organically combine the political advantages of the party's overview of the overall situation and coordinating all parties with the advantage of government resource integration, the market competitive advantage and the mass mobilization advantage of social organizations to build an open social governance system with universal participation.

Sharing refers to the sharing of public interests, public values, and public spirit, not just the sharing of material results. "Sharing" means that all members of society share the fruits of social governance. Sharing is not the average share. We cannot simply understand "sharing" as the process of equal distribution of reform results, nor can we equate "sharing" with egalitarianism and equal distribution (Huang \& Mao, 2016). Sharing is common and fair sharing, which makes the fruits and benefits of social development benefit everyone.

The pattern of social governance is a structural relationship of social governance order. This relationship is: the relationship of power, obligation and restriction between Stakeholder governance in the field of social governance. It indicates that relevant parties and subjects can how to implement governance to solve the problems of inconsistent interests and power imbalance between them (Zhu \& Wang, 2018). This governance pattern plays a fundamental role in the effects of social governance and governance order.

\section{Significance}

China is in a critical period of deepening reform. With the rapid economic development and rapid urbanization, various social contradictions appear frequently such as the imbalance in economic development between regions, the growing gap between rich and poor in urban and rural areas, and the imperfect social security system. It is a difficult problem for the party and government to 
improve social governing methods and the effectiveness of social governance, and achieve "good governance" under the situation of increasingly prominent social contradictions. In order to meet the needs of the times, the report of the $19^{\text {th }}$ Party Congress proposes an innovative path: "Creating a social governance pattern of co-construction, governance and sharing". Therefore, it is very important to create a social governance pattern of co-construction, governance and sharing, and its meaning is as follows.

\subsection{Conducive to Strengthening Socialist Democracy}

Society belongs to everyone. Therefore, social governance must also involve all people and enjoy the fruits of social governance. It is also the essential requirement of co-construction and governance. Moreover, people are the creators and promoters of history which requires the broad participation of all people and workers in the process of social governance (Xun, 2016). In addition, the essence of socialism is to eliminate polarization and ultimately achieve common prosperity through the development of productivity. But, at present, there are many factors that are detrimental to our common prosperity in the course of economic development. The fruits of China's rapid economic growth have not been shared by all levels of society, but mostly enjoyed by a small number of people. The development between regions and between urban and rural areas is also very uneven. The concept of co-construction and co-governance is to overcome and solve the problems existing in development, and helps to make all people share the fruits of reform and development. In short, the social governance pattern of co-construction, co-governance, and sharing is a governance pattern of "everyone participates, everyone does its best, and everyone enjoys it". It is an essential requirement that highlights the people's subjective status and is conducive to strengthening socialist democracy (Xun, 2016).

\subsection{Conducive to Deepening Social Governance Reform}

Social governance, as one of the national governance systems, places more emphasis on multiple interactions and co-governance, as well as "consensus, win-win cooperation, and healthy interaction". Moreover, social governance is a longterm, systematic and complex project. However, in the current social governance of China, the party and the government take most of the responsibilities, the participation of the public and the construction of the legal system are weak, so It is necessary to carry out social governance reforms and strive to build a social governance structure in which all the people build, manage and share. The social governance pattern of building a common governance and sharing is conducive to breaking the absolute monopoly position of the party and the government on social governance, so that all people become the main participants in social governance. And it will help all citizens to participate in social governance as the main body of governance, and they can promote their own initiative and creativity in social governance. Therefore, it can effectively promote the improve- 
ment of social governance.

\subsection{Conducive to Innovation in Social Governance}

With the continuous development of society, the social situation is becoming increasingly complex and diversified, which has prompted the social governance structure to continuously improve its own governance content and governance methods. In other words, only innovation can keep the social governance pattern alive. Therefore, the social governance pattern of co-construct, co-governance and sharing will inevitably be the product of innovation in social governance in the new era. Since the reform and opening up, great changes have taken place in Chinese society. With the increase of the urbanization rate, China is gradually realizing a major change from a rural society to a dominant urban society. And it is difficult for the public to participate in social management because of the diversity of interests. At present, the reform has entered the deep-water area. And how to carry out effective innovation in social governance is the key to improving the effectiveness of social governance. Creating a social governance pattern of co-construction, governance and sharing requires all people to participate in the process of social governance and enjoy the fruit of reform and development together, we must improve the effectiveness of social governance, which will inevitably promote the innovation in social governance.

\subsection{Conducive to Promoting Value Sharing}

If social governance is not committed to maximizing public interests, failing to abide by public values, or promoting the public spirit, then it is impossible to build a social organic "community" and realize the sharing of material results. Only by achieving the sharing of public interests, public values, and public spirits, can we truly realize the sharing of material results that social governance requires in the process of building a social organic community. As the main body of social governance, the relationship between the government, the market, and society is particularly important to build a social governance pattern of co-construction, governance and sharing. Creating a social governance pattern of co-construction, governance and sharing is conducive to the government, the market, and society work together and learn from each other to solve social problems, meet social needs, create social value, achieve good governance and build a better society.

\section{Problem}

Many problems have been encountered in creating a social governance pattern of co-construction and governance and sharing. Problems are as follows.

\subsection{The Constraints of Traditional Social Governance Concepts}

Because the concept of governance is not very mature in China, people do not fully understand the essence of governance. Moreover, the idea of the govern- 
ment as the main body of governance that has been formed in China for a long time has become obsolete, which is out of the age. Although the Third Plenary Session of the $18^{\text {th }}$ Central Committee proposed the innovative concept of transforming "social management" into "social governance", which clarified the status and function of the public in social governance, the role of this idea in specific work is not very helpful, and the word "guan" is still the only way for many governments to govern society, which ignores the status of the public in social governance (Gao, 2018). At the same time, although the role of social organizations is very important in the specific social governance work, the government has not regarded them as equal objects in the process of social governance (Yang et al., 2016), resulting in the role of social organizations in social governance cannot be fully exerted, and it is not conducive to the coordination between the government and social organizations, therefore, hinders the formation of a social governance pattern in which the whole people build, shares and governs.

\subsection{Decentralized Social Governance Responsibilities and Disorderly Public Participation}

Under the background of the new normal, the public's awareness of participation is getting stronger and stronger. With the maturity and popularity of social networks, mobile Internet, and smart terminals, the public's channels for participating in social governance are more convenient and diversified, and the environment for personal expression of wishes and demands is also more relaxed, people has more freedom than before, but this freedom is becoming disorderly and excessive, because in the era of "Internet+", a large number of new social service fields have emerged that requires the joint participation and governance of multiple governance subjects. However, in this process, it is easy to cause mutual inferences and the problems of vacancy, offside or even dislocation because of the unclear responsibilities, it has caused the dispersion of governance responsibilities, led to disorderly or excessive participation of the public in social governance, and increased the difficulty of social governance (Huang \& Mao, 2016; Xiao, 2018). Therefore, how to improve the effectiveness of governance and enable citizens to participate in an orderly manner is a major issue that social governance must solve in the context of the new normal.

\subsection{Lack of Social Security Mechanisms}

In the social governance pattern of co-construction and common governance, the main body of social governance is everyone. However, due to the imperfect interest expression mechanism, the inadequate benefit coordination mechanism, the incomplete benefit protection mechanism, the lack of a social security system, the lack of public participation in governance and insufficient participation, the problems are more prominent (Xun, 2016). Some prominent issues in current social governance, such as mass incidents, are mostly caused by the fact that 
people's legitimate rights and interests are not effectively protected. A large part of the factors that cause this phenomenon are the current interest protection mechanism is not comprehensive and there are loopholes, which provide opportunities for criminals to find a way out. This is extremely detrimental to the construction and improvement of the social governance pattern for the nationwide construction, co-governance and shared social governance.

\subsection{Lagging Social Governance}

Social governance methods mainly refer to the specific methods adopted by social governance subjects in the governance process, which are very important in social governance. But there is a lag in the current governance methods in China, and social governance methods are not legalized and refined. There are many disadvantages such as the lack of humanization in social governance. These disadvantages are formed in the long-term development of traditional social management concepts. This is mainly because the government has failed to take the concept of social governance as the core of social governance. Moreover, due to the limitations of traditional governance thinking, China's social governance content is not rigorous, rational and systematic, the main responsibility of social governance is not clear, and the government's social governance is in a leading position, which will inevitably restrict the governance effectiveness of social governance pattern of co-governance and co-governance (Gao, 2018).

\subsection{The Government Leads Social Governance}

In the context of the new normal, social governance needs to give full play to the role of party leadership, government leadership, social coordination and public participation. Among them, party committees, governments, social organizations, and the public are the common components of the main body of social governance and are indispensable (Xun, 2016). To create a social governance pattern of co-construction and common governance for the whole people, we need to give full play to the role of social organizations and the public in social governance, make the subject of social governance more diverse, and thus achieve a social pattern of good governance. However, in the specific social governance practice, the social phenomenon of a single social governance subject and the government's complete dominance of social governance exists widely (Jia \& Wang, 2018). The participation of social organizations and market organizations is far from enough. The development of social organizations is immature and there is insufficient space for their survival and development. Many organizations have obvious administrative colors, small organizations, and small functions. Although the government has always emphasized the necessity to build a service-oriented government, this sense of service has not been strengthened, and the public's participation in social governance is also obviously insufficient, which is extremely detrimental to the construction and improvement of the social governance pattern for the whole people. 


\section{Solution}

\subsection{Change Governance Thinking and Innovate the Concept of Social Governance}

The prerequisite and basis for improving the social governance structure and enhancing the effectiveness of social governance are the innovations in social governance concepts. Old and aging social governance concepts not only cannot meet the needs of the times, but also restrict the performance of social governance. Therefore, the first method to build a social governance pattern of co-construction and co-governance for all is to establish a new concept of social governance centered on co-construction and co-governance for all. The government must break through the limitations of the dual cognition of "management" and "regulation" in the past and treat the people as one of the subjects in social governance, not just the object. At the same time, the government should gradually change its mindset, continuously deepen its understanding of itself, and strive to change its status from "athlete" to "referee". Moreover, the government also needs to simplify administration and decentralization, and return the content that is not in the scope of administrative functions to the society. In social governance, the government needs to actively change the working style, establish a good working style, and conduct more consultations and interactions with the people. Through new methods of handling to safeguard the legitimate rights and interests of the people, improve the relationship between the government and the people, and let all people participate in social governance and enjoy the development results brought by reform and opening up (Gao, 2018).

\subsection{Strengthen the Construction of Social Governance System and Improve the Social Governance System}

Institutional construction is the key to the construction of a social governance pattern for the entire people, and it is also an inevitable way to create a new social governance pattern of co-construction, governance and sharing. Only when the system construction is continuously improved can the people be able to participate in the process of social governance, and finally achieve the goal of a comprehensive social governance pattern of co-construction, co-governance and sharing. However, the current system construction is still imperfect, mainly manifested in the lack of interest expression, coordination, and maintenance mechanisms. Therefore, first of all, we must improve the mechanism of interest expression. The government needs to constantly improve the channels for expressing statutory appeals, such as administrative reconsideration, arbitration, and litigation, and give full play to the interests of the people's congress and the CPPCC (Cui, 2016). In addition, the government should actively carry out petition activities in the sunshine and broaden the channels for petitions. Second, we need to improve the interest coordination mechanism. Interest disputes will inevitably arise in the process of social governance. Therefore, the government must coordinate the relationship between actual and long-term interests, indi- 
vidual interests, and collective interests by constructing a comprehensive interest coordination mechanism to avoid the adverse consequences of conflicts of interest. Finally, we need to improve the interest protection mechanism. It is difficult to effectively protect people's vital interests, which will restrict public participation in social governance. Therefore, the government must effectively protect people's legitimate rights and interests. In addition, in order to ensure the effective implementation of social governance, it is also necessary to improve the social governance system of party committee leadership, government responsibility, social coordination, public participation, and the protection of the rule of law, and to improve the socialization, rule of law, intelligence, and professionalism of social governance.

\subsection{Strengthen the Construction of Community Governance System}

With the continuous advancement of social governance practices, people are becoming increasingly aware of the important role of urban and rural communities in social governance. As the basic unit of social governance, urban and rural communities are the center of social governance (Cui, 2018). Therefore, in order to accelerate the creation of a social governance pattern of co-construction, governance, and sharing, we must improve the new pattern of grass-roots social governance with grassroots party organizations as the core and the participation of the whole society, and guide the wide participation of various social forces such as resident units, social organizations, group organizations, etc, give full play to all aspects of society, and improve the service and management functions of urban and rural communities. It is necessary to put resources, services, and management at the grassroots level as far as possible, so that the grassroots have the right and resources to better provide accurate and effective services and management to the masses. It is necessary to strengthen the normalized management of the city, focus on the prominent problems that the people report strongly, pay close attention to the management of the chronic problems of urban management, and at the same time strengthen the management of floating population ( $\mathrm{Ma}, 2018)$, and make more use of marketization and rule of law to promote the orderly flow of population. The key to creating a new social governance pattern of co-construction, governance and sharing lies in implementation. It is necessary to build a public safety system, improve the production safety system and the community governance system, and strive to build a safe China to ensure that the people live and work in peace and social harmony and stability.

\subsection{Strengthen Technical Support Based on Information Governance}

Due to the diversity and breadth of its governance subjects, and the complexity of governance issues, it is necessary to strengthen technical support based on information governance. By establishing the concepts of interoperability, coopera- 
tion, and sharing, a new pattern of "Internet+" social governance that is "everyone has responsibility and everyone is responsible" is formed. Efforts should be made to eliminate obstacles to information sharing and establish an information exchange framework for social governance. It is necessary to establish an active mechanism to eliminate obstacles to information sharing and a framework structure for social governance information exchange. Promote the integration of governance data and establish a smart service model for social governance. This requires breaking down the barriers to departmental interests, eliminating departmental divisions, promoting the integration of departmental data, and providing smart services to the public in social governance with core technologies such as cloud platforms and cloud services (Yan \& Ren, 2018). The provision of smart services through the innovation of social governance platforms, systems and mechanisms is the main lesson we can learn from the social governance pattern of the urban area. And ensure the privacy and security of the governance process and form a good information sharing cultural environment.

\subsection{Improve the Legal System Guaranteed by the Rule of Law}

The guarantee of the rule of law is an important part of the innovation of the social governance system, and it provides a fundamental guarantee for the construction of a co-governance and shared social governance structure. By perfecting the legal system guaranteed by the rule of law and governing it, we must promote the construction of a co-construction, co-governance, and shared social governance structure. We need to look at social governance issues with a rule of law thinking. This requires cultivating the culture of the rule of law and promoting the spirit of the rule of law. It is also necessary to transform social governance from the past "rule of man" thinking to "rule of law" thinking, effectively improve the level of rule of law (Xia, 2018), and make the rule of law play a decisive role in social governance. It is necessary to implement the rule of law approach to social governance issues. The rule of law is the most effective way to ensure fairness and justice in social governance. This requires strengthening the legislative work in the field of social governance, establishing and improving legal systems and institutional systems related to social governance, and putting the solution of social governance issues into the track of the rule of law. In addition, it is necessary to innovate the social governance model with the rule of law model. Coordinate the diversified social governance forces through the thinking and methods of the rule of law, coordinate conflicts of social interests, regulate social behavior, and regulate social relations; strengthen the building of the basic system of social governance, and formulate a set of social governance within the framework of the rule of law standard system and public service operation procedures, with standardized operating procedures to ensure that the government fulfills its statutory social governance responsibilities, and to ensure that all people participate in social governance activities within the framework of law and order. 


\section{Conflicts of Interest}

The author declares no conflicts of interest regarding the publication of this paper.

\section{References}

Cui, D. H. (2018). Research on the Promotion Path of Building a Co-Construction, Governance and Shared Social Governance Pattern in the New Era. Modern Economic Information, 24, 19-21.

Cui, S. Y. (2016). Constructing a New Social Governance Model of Building, Sharing and Governing Together. Masses, 10, 55-56.

Gao, B. (2018). Social Governance Pattern of Co-Construction, Co-Governance and Sharing: Evolution Trajectory, Dilemma Analysis and Path Selection. Theoretical Research, 6, 67-74.

Huang, C., \& Mao, S. S. (2016). Persist in Shared Development and Build a Social Governance Pattern of Co-Construction and Sharing by the Whole People. Hebei Enterprises, 12, 168-169.

Jia, D. R., \& Wang, G. A. (2018). Strive to Build a Social Governance Pattern of Co-Construction, Governance and Sharing. Journal of the Party School of Shanxi Provincial Committee of the Communist Party of China, 41, 117-119.

Jiang, G. H., \& Liu, W. J. (2018). Theoretical Interpretation of Xi Jinping's Governance Concept of "Co-Construction, Common Governance and Sharing". Solicitation, 1, 32-38.

Li, J. Y. (2017). Accurately Grasp the Connotation of "Building a Social Governance Pattern of Co-Construction, Common Governance and Sharing" in the New Era. Journal of the Party School of CPC Nanjing Municipal Committee, 6, 110-112.

Ma, L. J. (2018). Creating a Social Governance Pattern of Co-Construction, Co-Governance and Sharing. Journal of Tianshui College of Administration, 19, 40-43.

Xia, J. W. (2018). Social Governance Pattern of Co-Construction, Co-Governance and Sharing: Theoretical Construction and Practical Exploration. Jiangsu Social Sciences, 3, 53-62.

Xiao, D. (2018). Creating a Community Governance Pattern of Co-Construction, Governance and Sharing. People's Forum, 16, 78-79.

Xun, Y. (2016). Research on the Social Governance Pattern of Building a Nationwide Co-Construction and Sharing. Human Resource Management, 5, 16-17.

Yan, K. G., \& Ren, B. B. (2018). Co-Constructing, Governing and Sharing Social Governance Pattern: Value, Structure and Promoting Path. Hubei Social Sciences, 5, 46-52.

Yang, H. et al. (2016). Research on Constructing Social Governance Patterns of Common Development and Sharing among the People. Journal of the Party School of CPC Jinan Municipal Committee, 5, 68-71.

Zhu, X. W., \& Wang, M. B. (2018). Social Governance Pattern of Co-Construction, Co-Governance and Sharing: Theoretical Interpretation and System Construction. Journal of Xinjiang University (Philosophy, Humanities and Social Sciences), 46, 19-25. 